\title{
A estética no sistema de braquetes autoligáveis
}

\author{
Daniel J. Fernandes*, Rhita C. C. Almeida**, Cátia C. A. Quintão***, \\ Carlos N. Elias ${ }^{\star \star \star \star}$, José Augusto M. Miguel ${ }^{\star \star \star \star \star}$
}

\section{Resumo}

Introdução: os braquetes autoligáveis foram, inicialmente, idealizados com objetivo de otimização do tempo de atendimento clínico. Por dispensar qualquer tipo de amarração, inúmeras vantagens foram atribuidas a este sistema, com a redução da fricção superficial na interface braquete/fio ortodôntico. Com esta redução, são necessárias forças de menor intensidade para o estabelecimento da movimentação dentária, realizada, assim, de uma forma mais rápida e eficiente. Em decorrência da maior demanda estética por parte dos pacientes, os braquetes autoligáveis começaram a ser confeccionados em policarbonato, promovendo ganhos estéticos únicos, quando em comparação a seus anólogos metálicos. Objetivo: realizar uma revisão de literatura sobre o sistema de braquetes autoligáveis estéticos.

Palavras-chave: Fricção superficial. Braquetes estéticos. Modo de ligação. Ortodontia.

\section{INTRODUÇÃO}

O uso cada vez mais freqüente de mecânicas de deslizamento tornou o controle do atrito em Ortodontia uma das principais preocupações para o sucesso do tratamento planejado. $\mathrm{O}$ atrito pode ser definido como uma força que se opõe ou retarda a movimentação de dois corpos que se encontram em contato. Diferentemente do uso de alças, onde o atrito gerado é mínimo, o deslizamento responde por considerável quantidade de friç̧ão na interface braquete/fio ortodôntico ${ }^{1,10,11,12,14,15}$, sendo a dinâmica deste binômio essencial para o estabelecimento da movimentação ortodôntica. Diversas indicações são atribuídas à mecânica de deslizamento, tais como casos de fechamento de espaços, além da translação e retração de elementos para ocupação de áreas de extração $0^{1,10,11,12,15}$.

O conceito de braquetes autoligáveis surgiu em 1935 com o advento do sistema Russell Lock.
A partir desta data, já era preconizado um sistema que viabilizasse a otimização do tempo de atendimento e uma maior facilidade de união do sistema braquete/fio ortodôntico, com a menor quantidade de atrito possível ${ }^{11,13,14}$. A retenção do arco no interior da ranhura do braquete era obtida através de um sistema mecânico ajustado na superfície vestibular do artefato, funcionando como uma quarta parede da ranhura. O padrão de autoligação foi seguido e aprimorado por Wildman em 1972 com o sistema Edgelok ${ }^{11,13,15}$.

Hanson, em 1975, combinou o Sistema Edgewise preconizado por Angle com conceitos pessoais, desenvolvendo um aparato helicoidal autoajustável único, capaz de reter o arco e transmitir ao mesmo algum grau de ativação ${ }^{11,13,15}$. Apresentava, porém, algumas limitações inerentes à capacidade de distensão do sistema de molas segundo o qual a resposta da interação fio/braquete subordinava-se

\footnotetext{
* Aluno de Mestrado em Ortodontia-UERJ - Rio de Janeiro/Brasil.

** Aluna de Mestrado em Ortodontia-UERJ - Rio de Janeiro/Brasil.

*** Doutora em Ortodontia - UFRJ. Professora Adjunta,Ortodontia-UERJ-Rio de Janeiro/Brasil.

**** Doutor em Ciências dos Materiais - IME. Professor de Ciências dos Materiais - IME - Rio de Janeiro/Brasil.

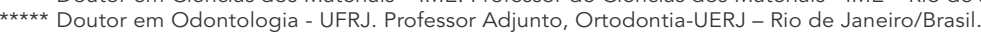


ao calibre do fio ortodôntico empregado.

Diversos outros tipos de braquetes autoligáveis foram idealizados, com variações de forma, tamanho, mecânica e material. Todavia estes artefatos, apesar de sua considerável capacidade de diminuição do atrito, nunca se difundiram de maneira permanente no cotidiano ortodôntico ${ }^{6}$. $\mathrm{O}$ alto custo e a inicial fragilidade apresentada por este sistema foram os principais responsáveis pela não ratificação do mesmo ${ }^{15,16}$.

Após o ano de 2000, com o surgimento de braquetes autoligáveis de menores dimensões, maior robustez e praticidade de manipulação, estes artefatos tornaram-se interessantes ao uso diário do ortodontista. Todavia, um maior apelo à estética foi observado por parte dos pacientes, redirecionando a uma nova tendência ${ }^{12}$. Estes começaram, então, a ser confeccionados em policarbonato. Estudos realizados por Cacciafesta et al. ${ }^{3}$ afirmam que o atrito produzido por este tipo de material apresenta-se como mais próximo ao observado em braquetes metálicos convencionais, apesar de superior ao mesmo. Contudo, pouco se observa na literatura sobre o comportamento deste dispositivo quando confeccionado em policarbonato, tornando-se necessária uma revisão de literatura sobre o assunto.

\section{REVISÃO DA LITERATURA \\ Fricção superficial e atrito}

Friç̧ão pode ser definida como a grandeza contrária à movimentação de um corpo em relação tangencial à superfície de outro, atuando em sentido oposto à tendência de deslocamento do mesmo $0^{1,11,14,15,18}$. A grandeza é abordada segundo seu coeficiente de fricção, resultado do quociente entre o módulo da força de fricção tangencial e a carga aplicada pela força normal, perpendicular ao movimento em análise ${ }^{10}$. Sua natureza pode ser decomposta em uma componente vertical, denominada força normal, que responde pela interação entre as superfícies de contato dos corpos envolvidos no movimento. Está também subordinada ao coeficiente de atrito, o qual se demonstra constante para cada tipo de material e é dependente de características físicas, tais como textura, rugosidade e dureza das superfícies envolvidas ${ }^{14,18}$. A fricção pode ser, ainda, dividida em duas outras forças, de acordo com estado de dinâmica ao qual o sistema se encontra submetido ${ }^{1,18}$. Ambas as grandezas são conhecidas como fricção estática e cinética, antagonistas ao estado de inércia apresentado, estando o corpo em repouso ou em movimento, respectivamente ${ }^{11}$. A componente estática muitas vezes apresenta-se como superior escalarmente à sua análoga dinâmica ${ }^{15}$.

O controle da friç̧ão existente durante o deslocamento do fio no interior da ranhura de braquetes torna-se crucial pelo fato da mesma influenciar diretamente a taxa e o tipo de movimentação dentária ${ }^{1}$ e, conseqüentemente, o grau de sucesso alcançado com a mecânica. Pode ser influenciada por inúmeras variáveis, como o tipo de material, dimensão, forma e angulação da interface fio/ranhura ${ }^{1-7,10,14-18}$, situações de umidade do meio ${ }^{12,13}$, forças de ligação e tipo de amarração $2,6,10,11,13,15$.

Em relação ao tamanho dos braquetes, os de menores dimensões demonstraram valores de fricção superiores aos de maiores dimensões ${ }^{10}$. Tal afirmação justifica-se pelo fato de braquetes menores permitirem uma maior tendência de inclinação dentária. Esta inclinação responde pelo estabelecimento de uma angulação na interface fio/braquete e, assim, o aumento da fricção superficial ${ }^{5,17,18}$.

Abordando-se a dimensão e forma dos fios ortodônticos, uma influência direta é observada com relação à quantidade de atrito gerada. Fios ortodônticos de maior secção transversa disponibilizam um maior preenchimento da ranhura do braquete envolvido ${ }^{15}$ e, conseqüentemente, uma maior área de contato com o mesmo, resultando em uma maior fricção superficial ${ }^{1,6,17}$. Um aumento do atrito também é observado quando fios retangulares são empregados. Esta desvantagem, porém, é consideravelmente suprida pelo controle de posições radiculares permitido por este tipo de fio durante a movimentação dentária. 
Viabiliza-se, assim, uma menor incidência de inclinações indesejadas que proporcionariam o estabelecimento de angulações, convergindo para um atrito resultante muito superior ao aferido em conseqüência apenas da secção retangular transversa do material ${ }^{4,13,17,18}$.

\section{O atrito e a clínica ortodôntica}

O planejamento da movimentação dentária pode envolver diversos tipos de técnicas, estando o uso de mecânicas de deslizamento muito presente no cotidiano da clínica ortodôntica. Contribui ativamente para o estabelecimento de forças de atrito em grau muito superior ao observado pela ativação de alças ou loops $s^{1,10,11,14,15}$. Diferentemente do uso de alças onde o atrito gerado é consideravelmente menor, o deslizamento responde por considerável quantidade de fricção $\mathrm{O}^{1,10,11,12,14,15}$.

Para que o movimento dentário seja estabelecido, é preconizado que a força exercida por um capilar sanguíneo seja aplicada sobre os tecidos de suporte dentário ${ }^{1,12}$. Esta força contudo, deve primeiriamente superar a resistência apresentada pela fricção gerada na interface braquete/fio. Quando altos níveis de atrito são observados neste conjunto, a força aplicada pode ser reduzida à ordem de até 60\% de sua intensidade original, podendo transcorrer, clinicamente, na dificultação da movimentação dentária desejada e em perda de ancoragem ${ }^{10,14}$. Diversas outras manobras clínicas também respondem pela geração de atrito. Dentre elas pode-se citar a aplicação de torques ativos e o alinhamento e nivelamento de elementos dentários ${ }^{10}$.

Devido à capacidade do atrito gerado de influenciar diretamente na velocidade e intensidade de movimentação dentária, seu controle torna-se crucial para o sucesso do tratamento ortodôntico planejado. Desta forma, qualquer dispositivo que viabilize sua redução deve ser analisado e estudado de maneira singular em cada caso. Observa-se, assim, uma indicação em potencial do emprego de braquetes autoligáveis. Estes dispositivos, quando confeccionados em materais não metálicos, ainda suprem a maior demanda observada por parte dos pacientes com relação à estética ${ }^{12}$. Todavia, pouco foi observado em literatura sobre o comportamento deste tipo de artefato quando confeccionado por polímeros resinosos. A observação do comportamento frente às situações clínicas que envolvam uma quantidade considerável de atrito se torna necessária.

\section{Composição dos braquetes estéticos}

Os braquetes estéticos podem ser compostos por diferentes materiais; dentre eles a matriz cerâmica e a resinosa são os mais empregados, por apresentarem maior semelhança à maioria das colorações evidenciadas à composição do esmalte dentário.

Os braquetes estéticos cerâmicos são compostos de 99,9\% de óxido de alumínio, podendo diferir segundo o modo de fabricação, sendo denominados de mono ou policristalinos ${ }^{10}$. Os artefatos compostos por matrizes resinosas são confeccionados, principalmente, a partir de policarbonatos. Inicialmente, sua composição abrangia apenas matrizes puras, o que tornava o material mais propenso a deformações, fraturas e manchamentos ${ }^{8}$. Uma nova composição foi, então, estipulada para sua constituição, abrangendo a incorporação de reforços cerâmicos e de fibras de vidro. Os incrementos cerâmicos são observados nos sistemas autoligáveis Opal (Ultradent, South Jordan, EUA) e os de fibra de vidro no modelo Oyster (Gestenco, Gothemburg, Suíça) e Damon 3 (Ormco, Glendora, Califórnia, EUA). A modificação das matrizes do material garantiu uma superior resistência, estabilidade e menor suscetibilidade ao manchamento ${ }^{8,9}$, apresentando, contudo, valores de dureza e rigidez inferiores quando comparados aos braquetes de aço inoxidável e os de matrizes cerâmicas ${ }^{19}$.

O único modelo de braquetes autoligáveis translúcidos não confeccionados em policarbonato é o In-Ovation estético (GAC, Nova Iorque, EUA). Sua manufatura em cerâmica abrange a associação da matriz policristalina à liga de aço 
inoxidável responsável pelo revestimento de sua ranhura e do sistema de autofechamento anterior. Este padrão de emprego do material estético, em apenas uma fração diminuta do corpo do artefato, foi também utilizado pela Ormco (Glendora, Califórnia, EUA) no modelo Damon 3 , só que incorporando o policarbonato ao invés da cerâmica.

Considerando-se o método de confecção dos braquetes de policarbonato, Zinelis et al. ${ }^{19}$ afirmam ser a manufatura dos artefatos realizada sob a injeção de um único tipo de material. A impossibilidade de soldagem ou brazagem devida à não-resistência da matriz de policarbonato a estes procedimentos inviabiliza qualquer tentativa de confecção segmentada da base, corpo ou trava de precisão do artefato. Esta montagem a partir da união de diferentes partes é observada durante a manufatura dos braquetes de aço inoxidável, onde sua base possui rigidez inferior quando comparada a partes de seu corpo, como por exemplo as asas do artefato $^{19}$. Desta maneira assegura-se uma base composta por um aço inoxidável de módulo de elasticidade inferior e maior resiliência em relação às asas do mesmo artefato, reduzindo possíveis danos ao esmalte dentário durante a descolagem ${ }^{19}$.

\section{O sistema de braquetes autoligáveis}

O sistema autoligável difere dos demais pela logística mecânica presente em sua ranhura, que responde pela permanência do fio ortodôntico em seu interior. Pode ser observada a existência de uma
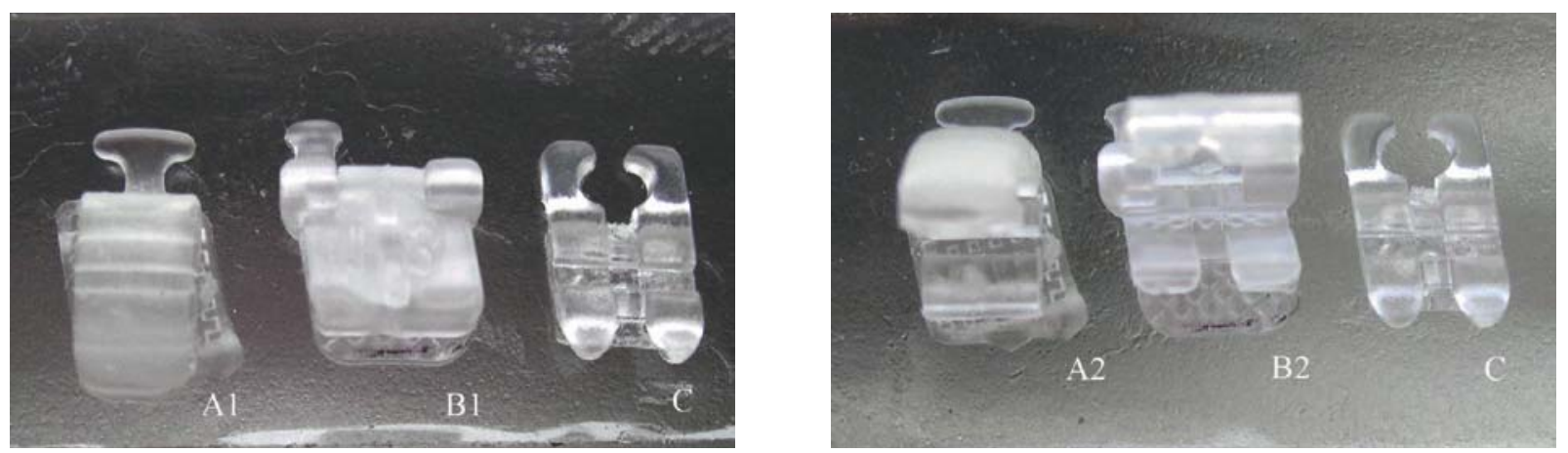

FIGURA 1 - Braquetes confeccionados em policarbonato em vista frontal. (A) Braquete autoligável Opal (Ultradent $\left.{ }^{\circledR}\right)$; (B) Braquete autoligável Oyster (Gestenco ${ }^{\circledR}$ ); (C) Braquete convencional Blonde (GAC $\left.{ }^{\circledast}\right)$. Notar a cobertura estética rebatível em posição (1) fechada e (2) aberta. cobertura metálica de material semelhante ao empregado na manufatura do braquete. Esta cobertura sofre encaixe na abertura da ranhura, funcionando como uma quarta parede do mesmo e transformando-o à semelhança do que seria um tubo ortodôntico (Fig. 2A, B). Este sistema observado em diversos dispositivos (Tab. 1) segue a metodologia idealizada pelo modelo Russel Lock ${ }^{11,13,15}$.

O outro modelo autoligável existente caracteriza-se como transcorrendo do padrão desenvolvido por Hanson ${ }^{4}$, em 1975, (Tab. 1), ancorando-se na existência de uma mola de material resiliente, que garante a reclusão do fio ortodôntico no interior da ranhura dos braquetes. Todavia, o resultado desta interação está subordinado ao calibre do fio empregado. Este sistema originou a logística em uso conhecida como spring clip $p^{1,5,12,15,16,17}$ ou sistema ativo resiliente.

Por ser a união do binômio braquete/fio ortodôntico realizada através do dispositivo mecânico de autoligação, inúmeras vantagens foram atribuídas à logística apresentada por esse tipo de artefato. Dentre elas, pode-se citar a maior facilidade e rapidez no momento de associação do fio à ranhura do braquete ${ }^{7,13,14,17}$, um menor tempo de cadeira por atendimento e de tratamento, maior conforto e maior facilidade de higienização por parte do paciente ${ }^{7,13}$, a diminuição das chances de quebra da cadeia de biossegurança e de infecções cruzadas ${ }^{13}$ pelo fato de ser empregada uma quantidade menor de instrumentais ${ }^{6}$ e a manutenção de forças 

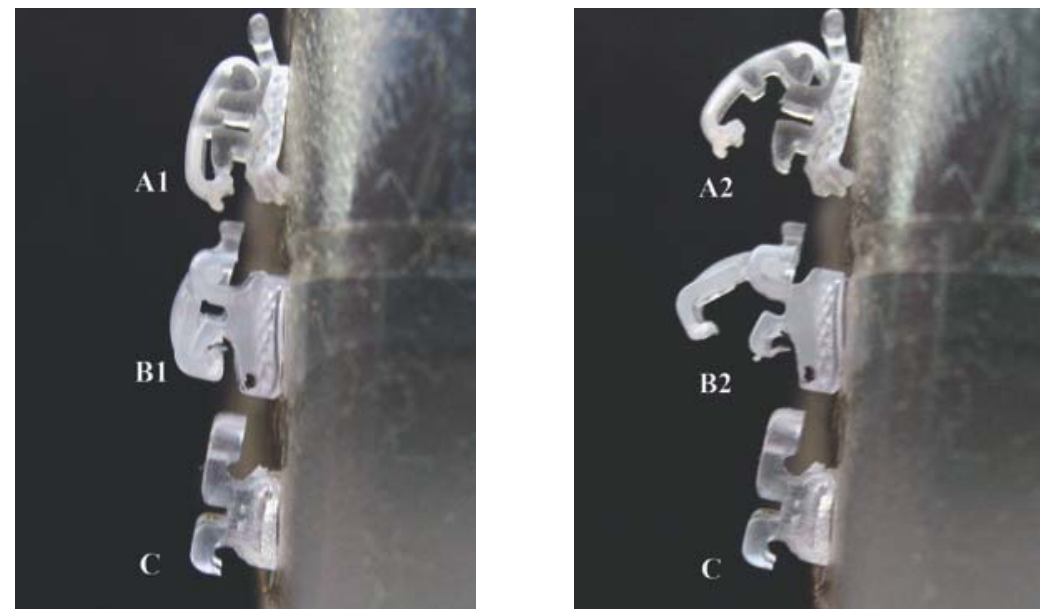

FIGURA 2 - Braquetes confeccionados em policarbonato em vista lateral. Comparação de 2 sistemas autoligáveis (A) Opal (Ultradent ${ }^{\oplus}$ ) e (B) Oyster (Gestenco $0^{\oplus}$ em comparação com o (C) Braquete convencional Blonde (GAC ${ }^{\circledast}$. Observar a cobertura estética rebatível em posição (1) fechada e (2) aberta.

Tabela 1 - Comparação entre os sistemas mecânicos e anos de surgimento dos sistemas de braquetes autoligáveis ${ }^{2,14}$.

\begin{tabular}{|c|c|c|}
\hline Braquetes autoligáveis & Sistema mecânico & Ano \\
\hline Russel Lock ${ }^{\circledR}$ & Tampa anterior passiva & 1935 \\
\hline Ormco Edgelock ${ }^{\circledast}$ & Tampa anterior passiva & 1972 \\
\hline Orec Speed ${ }^{\circledR}$ & Resiliente ativo (spring clip) & 1980 \\
\hline A Company Activa ${ }^{\circledR}$ & Tampa anterior passiva & 1986 \\
\hline Adenta Time ${ }^{\circledR}$ & Resiliente ativo (spring clip) & 1994 \\
\hline Ormco Damon $2^{\circledR}$ & Tampa anterior passiva & 2000 \\
\hline GAC In-Ovation ${ }^{\circledR}$ & Resiliente ativo (spring clip) & 2000 \\
\hline GAC In-0vation $\mathrm{R}^{\circledR}$ & Resiliente ativo (spring clip) & 2002 \\
\hline $\begin{array}{l}\text { Gestenco Oyster Aesthetic } \\
\text { System }^{\circledR}\end{array}$ & Tampa anterior passiva & 2003 \\
\hline Ormco Damon $3^{\circledR}$ & Tampa anterior passiva & 2005 \\
\hline $\begin{array}{l}\text { Ultradent } \quad \text { Opal Aesthetic } \\
\text { System }^{\circledR}\end{array}$ & Tampa anterior passiva & 2006 \\
\hline GAC In-Ovation estético ${ }^{\circledR}$ & Resiliente ativo (spring clip) & 2006 \\
\hline
\end{tabular}

mais constantes e duradouras sobre o elemento dentário.

Uma redução da fricção superficial é intrínseca $^{1,2,5-11,13,15,16,17}$ a este tipo de dispositivo, exatamente por dispensar qualquer tipo de agente externo de ligação. Todavia, em casos de braquetes autoligáveis resinosos, por haver a priorização da estética do paciente ${ }^{12}$, desvantagens clínicas talvez possam ser observadas. Trata-se da possibilidade de aumento da fricção superficial apresentada por este tipo de material. Este aumento refere-se às possíveis elevações da rugosidade e do coeficiente de atrito apresentado pelos polímeros resinosos.

\section{DISCUSSÃO}

A fricção superficial é considerada uma grandeza multifatorial, estando a mesma subordinada a interações existentes entre o fio ortodôntico e o braquete e à forma como estes dispositivos encontram-se ligados ${ }^{9,11,15,16}$.

O comportamento dos fios ortodônticos, apesar de também depender de sua interação com a ranhura dos artefatos, é principalmente governado por características intrínsecas próprias. Tais características seriam suas propriedades físicas, abrangendo a rugosidade, dureza e flexibilidade do material $1^{9,11,17}$. A rugosidade responde pela modulação do coeficiente de atrito, sendo estas grandezas diretamente proporcionais e responsáveis pela intensidade de fricção superficial produzida ${ }^{9}$. A dureza dos fios também tem participação na intensidade friccional produzida, dependendo, porém, da força normal observada após o contato do material com a ranhura dos braquetes ortodônticos ${ }^{11}$. Este contato, geralmente, apresenta-se mais presente em fios com menor dureza e maior flexibilidade. 
Quanto aos modos de ligação convencionais, é empregado o uso de amarrilhos metálicos ou elásticos. Ligaduras elásticas, apesar de sofrerem deformação permanente em decorrência da hidrólise térmica ou estiramento em meio bucal, são preferidas, em decorrência de sua mais simples e fácil forma de manuseio no cotidiano clínico. Contudo, apresentam uma superior contribuição para o aumento da fricção em decorrência do alto coeficiente de atrito de alguns materiais borrachóides, como o poliuretano ${ }^{1,15,16}$. O amarrilho metálico, por sua vez, demonstra um coeficiente de atrito consideravelmente inferior ao de seu análogo elástico, uma superior efetividade e longevidade na forma de amarração, além de facilitar a higienização por parte do paciente, por propiciar uma menor retenção de biofilme bacteriano ${ }^{14,15,16}$. Desvantagens de tal sistema estariam no maior tempo de cadeira e complexidade de manuseio deste material, além da falta de padronização da força empregada por esta amarração no complexo braquete/fio ortodônti$\mathrm{Co}^{15}$. Estas limitações, quando em associação à hidrólise e fricção superior, evidenciadas no sistema de ligação elástico, sinalizam para as vantagens de utilização clínica do sistema autoligável, por este independer de qualquer componente externo para para reclusão do fio ortodôntico.

Os braquetes autoligáveis são divididos em dois sistemas, de acordo com o tipo de dispositivo mecânico presente. $\mathrm{O}$ mecanismo conhecido como spring clip ou sistema ativo resiliente, resume-se à existência de uma mola metálica que garante a permanência do fio ortodôntico no interior da ranhura ${ }^{7,15,17}$. A alta resiliência desta mola garante a aplicação de forças mais constantes, fisiológicas e homogêneas, além de propiciar um maior controle da movimentação dentária nos 3 planos do espaço². Uma resposta simbiótica é observada quando este dispositivo é utilizado em associação a fios de, também, grande resiliência ${ }^{1}$. Todavia, quando objetivase o controle do atrito, a indicação deste sistema restringe-se a estágios iniciais de alinhamento e nivelamento, onde fios ortodônticos de menores di- mensões são empregados ${ }^{12}$. Esta limitação está relacionada à distensão da mola metálica, observada quando em interação com fios de secção transversa superior a $0,017^{\prime \prime 16}$. Nestes casos, o preenchimento da ranhura atinge o contato com a mola resiliente, tornando-a ativa na compressão do mesmo fio, resultando no aumento da fricção superficial.

O outro tipo de dispositivo mecânico autoligável é o encontrado no sistema de braquetes estéticos de policarbonato. Este mecanismo conforma-se à existência de uma tampa rebatível anterior, de mesmo material de composição dos braquetes, que garante a reclusão do fio ortodôntico em seu interior sem qualquer tipo de pressão ${ }^{11,12,16}$. Sua efetividade está na capacidade de aprisionamento do fio de maneira passiva, estética e com reduzido atrito ao deslizamento. Não se observam restrições quanto à secção transversa dos fios, estando seu uso indicado em qualquer estágio da terapia ortodôntica ${ }^{12}$.

Apesar da redução da fricção ser uma característica intrínseca do sistema de braquetes autoligáveis, esta propriedade é auxiliada por características estruturais observadas na aparatologia autoligada estética. O uso do policarbonato como material de escolha contribui para a manutenção da fricção superficial em níveis reduzidos ${ }^{8}$. Apesar deste material, como visto em literatura ${ }^{8}$, ser mais friável que outros análogos estéticos, a maior robustez observada na estrutura dos artefatos autoligáveis nãometálicos permite considerável resistência do mesmo à fratura ${ }^{3}$. Este aumento estrutural necessário no corpo dos braquetes não prejudica a estética do dispositivo, e o teórico aumento do atrito que seria esperado é completamente diluído pelos ganhos conseguidos por um sistema composto por policarbonato, que dispensa qualquer tipo de amarração.

\section{CONCLUSÃO}

O sistema de braquetes de policarbonato autoligáveis apresenta-se como uma valiosa opção no cotidiano clínico, em casos onde haja uma grande demanda estética. Esta configuração de braquetes permite o aprisionamento do fio ortodôntico de 
forma passiva, sem a participação de nenhum agente externo de ligação, promovendo a permanência da fricção superficial em índices reduzidos. Obtémse, assim, um tratamento mais rápido e confortável para o paciente, que possibilita a aplicação de forças ortodônticas de menor intensidade, além dos ganhos estéticos únicos promovidos pelo sistema autoligável, quando confeccionado em policarbonato.

\title{
The self-ligating system in an aesthetic view
}

\begin{abstract}
Introduction: The self-ligating system was introduced aiming the reduction of chair time. Once this system does not need any ligation form, several advantages were observed, such as the reduction on superficial friction in couple bracket/ orthodontic wire, and the reduction on the force level that is necessary to establish the orthodontic tooth movement. The growing demands of aesthetic patients induced the self-ligating system to be made of polycarbonate material, resulting in unique aesthetic advantages when compared with the metallic form of this system. Aim: The objective of this paper was to proceed with a literature review about aesthetic self-ligating brackets.
\end{abstract}

Key words: Superficial friction. Aesthetic brackets. Ligation mode. Orthodontics.

\section{REFERÊNCIAS}

1. BERGER, J. L. The influence of the SPEED brackets's self-ligating design on force levels in tooth movement: a comparative in vitro study. Am. J. Orthod. Dentofacial Orthop., St. Louis, v. 97, p. 219-228, 1990.

2. BERGER, J. L. The SPEED appliance: a 14 year update on this unique self-ligating orthodontic mechanism. Am. J. Orthod. Dentofacial Orthop. St. Louis, v. 105, p. 217-223, 1994.

3. CACCIAFESTA, V.; SFONDRINI, M. F.; RICCIARDI, A.; SCRIBANTE, A.; KLERSY, C.; AURICCHIO, F. Evaluation of friction os stainless steel and esthetic self-ligating brackets in various bracket-archwire combinations. Am. J. Orthod. Dentofacial Orthop., St. Louis, v. 124, p. 395-402, 2003.

4. HANSON, G. H. The SPEED system: a report on the development of a new Edgewise appliance. Am J. Orthod., St. Louis, v. 78 , no. 3, p. 243-65, 1980

5. HARRADINE, N. W. T.; BIRNIE, D. J. The clinical use of Activa self-ligating brackets. Am. J. Orthod. Dentofacial Orthop., St. Louis, v. 109, p. 319-328, 1996.

6. HENAO, S. P.; KUSY, R. P. Evaluation of the frictional resistance of conventional and self-ligating bracket designs using standardized archwires and dental typodonts. Am. J. Orthod. Dentofacial Orthop., St. Louis, v. 74, p. 202-211, 2004.

7. HENAO, S. P.; KUSY, R. P. Frictional evaluations of dental typodont models using four self-ligating designs and a conventional design. Angle Orthod., Appleton, v. 75, p. 75-85, 2004.

8. LIU, J.; CHANG, L.; CHUANG, S.; SHIEH, D. Shear bond strengths of plastic brackets with a mechanical base. Angle Orthod., Appleton, v. 72, p. 141-145, 2002

9. LOFTUS, B. P.; ARTUN, J.; NICHOLLS, J.; ALONZO, T. A.; STONER, J. A. Evaluation of friction during sliding tooth movement in various bracket-arch wire combinations. Am. J. Orthod. Dentofacial Orthop., St. Louis, v. 116, p. 336-345, 1999.

10. NISHIO, C.; MOTTA, A. F.; ELIAS, C. N.; MUCHA, J. N. In vitro evaluation of friction forces between archwires and ceramic brackets. Am. J. Orthod. Dentofacial Orthop., St. Louis, v. 125, p. 56-64, 2004.

11. PIZZONI, L.; RAVNHOLT, G.; MELSEN, B. Frictional forces related to self-ligating brackets. Eur. J. Orthod., Oxford, v. 20, p. 283-291, 1998.
12. READ-WARD, G. E.; JONES, S. P.; DAVIES, E. H. A comparison of self-ligating and conventional orthodontic bracket systems. Br. J. Orthod., Oxford, v. 24, p. 309-317, 1997.

13. REDLICH, M.; MAYER, Y.; HARARI, D.; LEWINSTEIN, I. In vitro study of frictional forces during sliding mechanics of reduced friction brackets. Am. J. Orthod. Dentofacial Orthop., St. Louis, v. 124, p. 69-73, 2003

14. SHIVAPUJA, P. K.; BERGER, J. A comparative study of conventional ligation and self-ligating bracket systems. Am. J. Orthod. Dentofacial Orthop., St. Louis, v. 106, p. 172-180, 1994

15. SIMS, A. P. T.; WATERS, N. E.; BIRNIE, D. J.; PETHYBRIDGET, R. J. A comparison of the forces required to produce tooth movement in vitro using two self-ligating brackets and a pre-adjusted bracket employing two types of ligation. Eur. J. Orthod., Oxford, v. 15, p. 377-385, 1993.

16. THOMAS, S.; SHERIFF, M.; BIRNIE, D. A comparative in vitro study of the frictional characteristics of two types of self ligating brackets and two types of pre-adjusted Edgewise brackets tied with elastomeric ligatures. Eur. J. Orthod., Oxford, v. 20, p. 589-596, 1998.

17. THORSTENSON, G. A.; KUSSY, P. Effect of archwire size and material on the resistance to sliding of self-ligating brackets with second order angulation in the dry state. Am. J. Orthod. Dentofacial Orthop., St. Louis, v. 122, p. 295-305, 2002.

18. THORSTENSON, G. A.; KUSSY, P. Effects of ligation type and method on the resistance to slinding of novel orthodontic brackets with second order angulation in the dry and wet states. Angle Orthod., Appleton, v. 73, p. 418-430, 2002.

19. ZINELIS, S.; ELIADES, T.; ELIADES, G.; MAKOU, M.; SILIKAS, N.: Comparative assessment of the roughness, hardness, and wear resistance of aesthetic bracket materials. Dent. Mater., [S.I.], v. 21, no. 9, p. 890-894, Sept. 2005.

Endereço para correspondência

Daniel J. Fernandes

FOUERJ - Departamento de Ortodontia

Blvd 28 de Setembro 157 - Sala 230

CEP: 20.551-030 - Vila Isabel - Rio de Janeiro

E-mail: fernandes.dj@gmail.com 